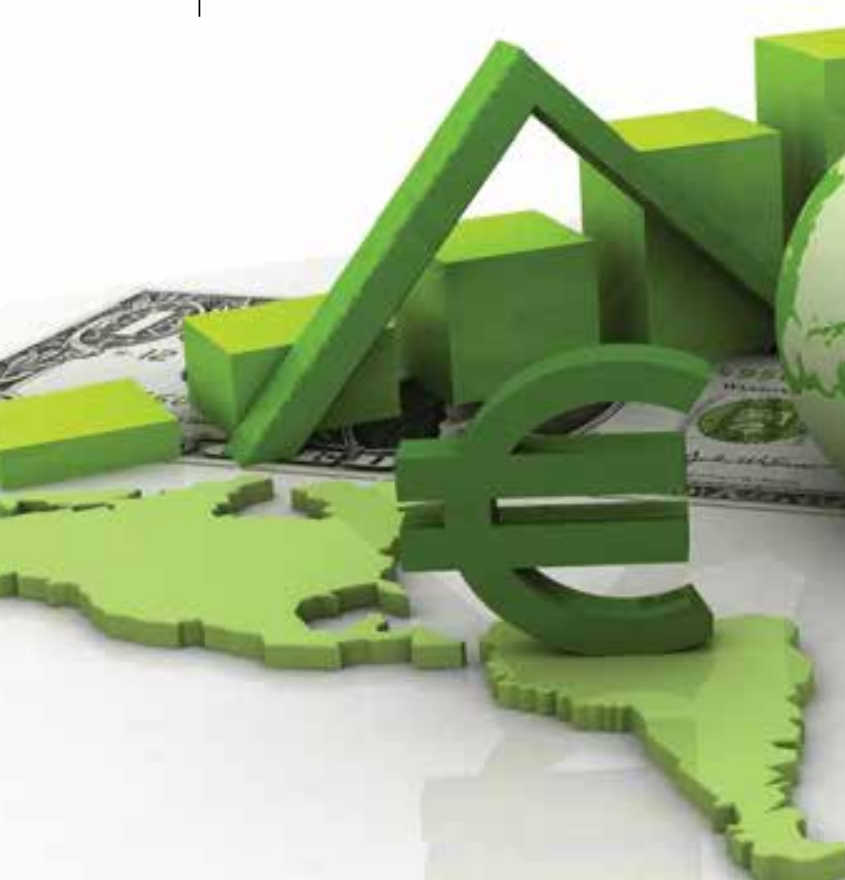

\title{
Considerações sobre \\ Desenvolvimento Econômico, \\ Economia Verde \\ e Contabilidade Ambiental: \\ uma abordagem introdutória
}

Renato Santiago Quintal

Capitão-de-Corveta (IM). Chefe do Departamento de Sistemas de Pagamento da Pagadoria de Pessoal da Marinha. Mestre em Ciências Contábeis (FAF/UERJ). E-mail: quintal@papem.mar.mil.br

Robson Augusto Dainez Condé

Auditor Fiscal da Receita do Estado do Espírito Santo. Mestre em Ciências Contábeis (FAF/UERJ).

E-mail: robsonconde@hotmail.com

Marcos dos Santos

Capitão-de-Corveta. Gerente de Projetos no Centro de Análises de Sistemas Navais. Doutorando em Engenharia de Produção (UFF). E-mail: marcossantos@casnav.mar.mil.br

Rodrigo Barreiros Leal

Capitão-de-Corveta (IM). Encarregado da Divisão de Análise Contábil da Diretoria de Coordenação do Orçamento da Marinha. Mestre em Ciências Contábeis (FACC/UFRJ).

E-mail: rodrigo.leal@corm.mar.mil.br

Carlos Francisco Simões Gomes

Professor Adjunto III do Programa de Pós-graduação em Engenharia de Produção (UFF). Doutor em Engenharia de Produção (COPPE/UFR)).

E-mail: cfsg1@bol.com.br 


\section{RESUMO}

$\mathrm{Na}$ atualidade, as discussões sobre meio ambiente vem se revestindo de crescente significância, passando a ser verificados especialmente sob a sua expressão em termos financeiros, habilmente traduzidos pelas ciências sociais aplicadas, notadamente a ciência econômica e a ciência contábil. Sob esse prisma, o objetivo do presente estudo é traçar um breve panorama acerca das temáticas afetas ao desenvolvimento econômico, economia verde e contabilidade ambiental. Nesse contexto, a pesquisa pode ser classificada como: exploratória, bibliográfica e qualitativa. A relevância do estudo reside na atualidade da matéria, a qual vem sendo discutida nos mais distintos fóruns.

Palavras-chave: Desenvolvimento econômico; Economia verde; Contabilidade ambiental.

\section{ABSTRACT}

Currently, discussions on the environment has been coating of increasing significance, becoming checked especially under its expression in financial terms, ably translated by applied social sciences, particularly economics and accounting science. In this light, the aim of this study is to outline brief overview themes about economic development, green economy and environmental accounting. In this context, the research can be classified as exploratory, bibliographical and qualitative. The relevance of this study lies in the present-day matter, which has been discussed in widely different forums.

Keywords: Economic development; Green economy; Environmental accounting.

\section{INTRODUÇÃO}

Nos dias atuais os debates sobre meio ambiente vem se revestindo de crescente significância, passando a ser verificados especialmente sob a sua expressão em termos financeiros, habilmente traduzidos pelas ciências sociais aplicadas, notadamente a ciência econômica e a ciência contábil.

Sob esse prisma, o objetivo do presente artigo é traçar um panorama acerca das temáticas afetas ao desenvolvimento econômico, economia verde e contabilidade ambiental. A relevância do estudo reside na atualidade da matéria, a qual vem sendo discutida nos mais distintos fóruns.

Nesse contexto, à luz da tipologia de Gil (2010), a pesquisa pode ser classificada como: exploratória (propicia maior familiaridade com o problema, com o propósito de torná-lo mais explícito), bibliográfica (desenvolvida a partir de material já elaborado, formado essencialmente de artigos científicos e livros) e qualitativa (empreendida para apreciar aspectos qualitativos de alguma questão).

0 artigo encontra-se dividido nas seguintes seções: Introdução; Desenvolvimento econômico; Questão ambiental; Economia verde; Contabilidade ambiental; Perspectivas futuras na seara ambiental para graduandos em ciências contábeis; Considerações finais e Conclusões; e Referências.

\section{DESENVOLVIMENTO ECONÔMICO}

Para Bonente (2007), é possível afirmar que o debate sobre desenvolvimento econômico, no contexto das teorias formuladas pós-guerra, reveste-se, a partir da década de 1980, de uma conotação secundária no debate mundial. Segundo a autora em tela, tal fato se deve, parcialmente, à verificação de que o desenvolvimento econômico, à luz do apregoado até agora, não fora capaz de promover uma melhor distribuição de renda e uma redução das desigualdades espaciais. Se as preocupações anteriores estavam debruçadas sobre a desigualdade entre os países, a partir deste momento, o foco se volta para as desigualdades individual e espacial. Outrossim, eram nítidos os danos ambientais da robusta produção industrial do período anterior. Notadamente neste caso, as discussões sobre meio ambiente, que vem se cobrindo de crescente magnitude, passam a ser verificadas a partir da dicotomia envolvendo desenvolvimento econômico versus preocupação ambiental (BONENTE, 2007).

Cavalcanti (2002) questiona sobre o esgotamento do modelo baseado na reprodução de comportamentos consumistas predatórios do meio ambiente, por meio da aceleração do crescimento econômico, alicerçado na retirada crescente de recursos naturais, associado ao despejo de volumes em larga escala de resíduos no ecossistema. As condições ambientais não são as mesmas daquelas verificadas em décadas passadas, o que torna o processo de 
recuperação ambiental mais dificultoso. A Figura 1 evidencia os desafios envolvidos na compatibilização entre o desenvolvimento econômico e a sustentabilidade ambiental.

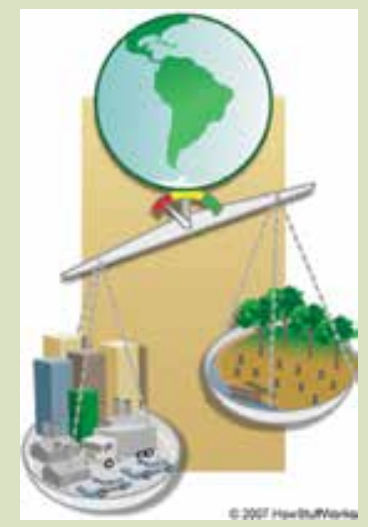

- Figura 1: Compatibilização entre o desenvolvimento econômico e a sustentabilidade ambiental.

Fonte: HowStuffWorks, 2007 apud Portal Biologia na Rede ${ }^{1}$

Cavalcanti (2002) destaca o pioneirismo de Celso Furtado em estabelecer uma relação entre economia e ecologia na década de 1970, por meio da sua obra "O Mito do Desenvolvimento Econômico". Para Cavalcanti (2002), a concepção do mito do desenvolvimento econômico está intrinsecamente associada à reflexão de Furtado de que o modelo da economia em expansão desmantela e degenera fortemente o meio ambiente, bem como fomenta a ilusão de que o crescimento econômico acarreta o desenvolvimento.

As evidências analisadas pela pesquisa de Macana (2008) revelam como modificações do clima representam um risco latente para o retrocesso do desenvolvimento humano e expansão das privações da humanidade no plano mundial, com desproporcionais reflexos em países pobres e em desenvolvimento. Macana (2008) destaca que os choques climáticos ameaçam os funcionamentos e capacitações dos indivíduos (notadamente nas searas da saúde e educação), os valores culturais e a as relações sociais. Adicionalmente, os choques climáticos são responsáveis por restringir o desenvolvimento humano quando afetam e limitam as condições necessárias ao sustento humano, majoritariamente pela diminuição da quantidade e da qualidade da água, da produção agrícola, da modificação das atividades pesqueiras (que vai ao encontro da reportagem

1 Portal Biologia na Rede. Disponível em: < http://bionarede.crbio04 gov.br/> Acesso em 23 jul. 2015 selecionada na seção anterior), da diminuição dos rendimentos econômicos, dentre outros aspectos. Nessas circunstâncias, a pesquisa de Macana (2008) identificou que os impactos maiores foram observados em áreas rurais, pela concentração da maior proporção de pobres.

Campos (2003) argumenta que, no final da década de 1970, emerge a abordagem unificada de planejamento e desenvolvimento, indicando a premência de integração entre aspectos econômicos e sociais. Segundo a autora em tela, é nesse período que a UNESCO insere o conceito de desenvolvimento integrado. Para Amaro (2009 apud Carvalho, 2010, p.17), o conceito de desenvolvimento integrado está associado à compreensão de o desenvolvimento deve integrar uma perspectiva sistêmica, holística e integrada de todo o processo.

\section{QUESTÃO AMBIENTAL}

Desde os primórdios da Revolução Industrial, atividades que eram desempenhadas de forma artesanal passaram a contar com uma participação maior das máquinas, geralmente servidas por combustíveis fósseis, produzindo mais produtos em menor intervalo de tempo. Em face da elevação da produção e consequente ampliação do consumo, um restrito grupo de empresários, acadêmicos e membros da sociedade civil, agrupou-se em 1968, na cidade italiana de Roma, para debaterem os caminhos de uma produção mais limpa e sustentável, nascendo, dessa forma, o Clube de Roma. No ano de 1972, esse mesmogrupo, solicitou ao Massachusetts Institute of Technology (MIT) um relatório que abordasse uma série de cenários, destacando de forma aberta à sociedade as alternativas que conciliassem o progresso sustentável e respeitasse as restrições ambientais. Esse documento foi publicado com o título"The Limits to Growth"(CLUBOFROME, 2013), conforme apresentado na Figura 2.

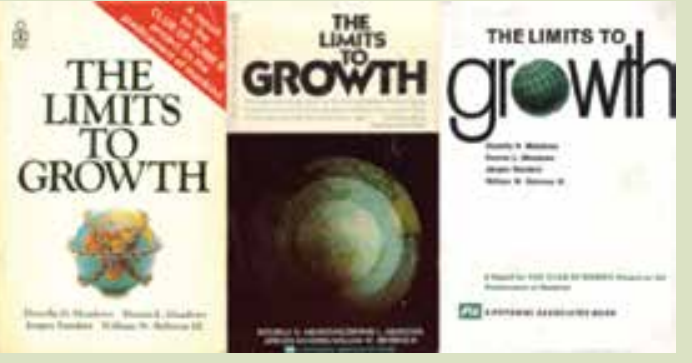

- Figura 2: Versões da obra "The Limits to Growth", do ano de 1972

\section{Fonte: Portal Limits to Growth ${ }^{2}$}

2 Portal Limits to Growth. Disponivel em: https://limitstogrowthnet. 
No mesmo ano, na cidade sueca de Estocolmo, foi realizada a primeira Conferência das Nações Unidas para o Meio Ambiente e Desenvolvimento, propondo como temática central o desenvolvimento sustentável. Contudo, as alterações nos rumos não eram simples; duas décadas mais tarde, aconteceria no Rio de Janeiro a ECO-92, outro encontro sobre o meio ambiente, conforme apresentado na Figura 3.

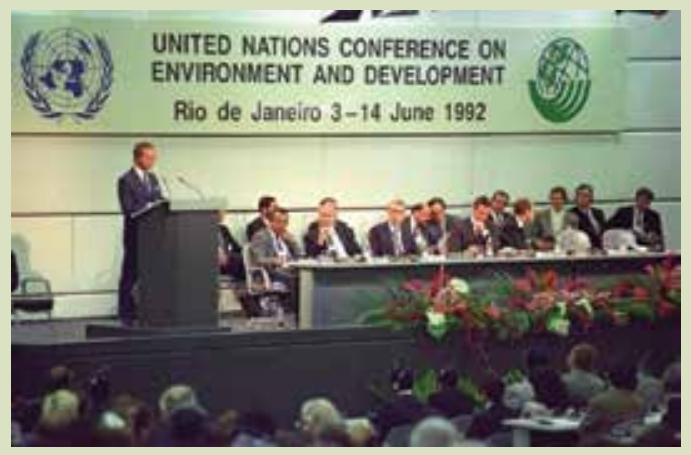

- Figura 3: Conferência das Nações Unidas sobre o Meio Ambiente e Desenvolvimento (ECO-92)

\section{Gonte: Portal Colégio Web ${ }^{3}$}

Duas décadas após sediar a ECO-92, o Rio de Janeiro sediou o evento Rio+20, ilustrado na Figura 4, mais uma conferência da Organização das Nações Unidas (ONU) sobre meio ambiente e desenvolvimento.

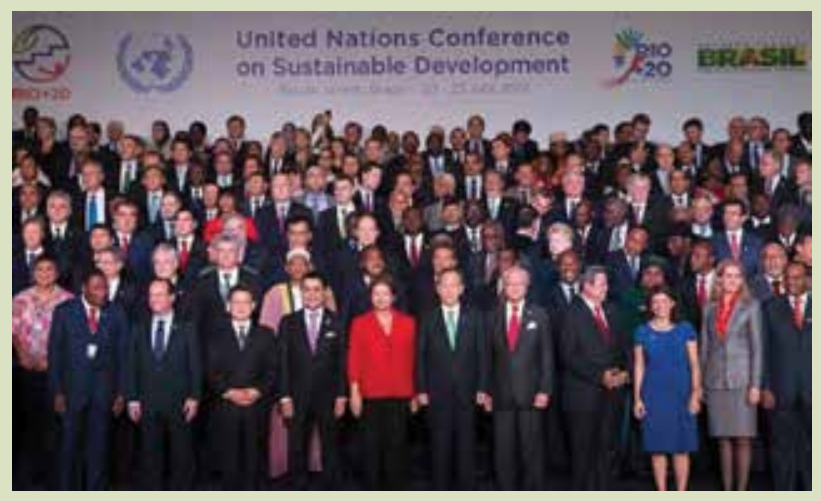

- Figura 4: Conferência das Nações Unidas sobre Desenvolvimento Sustentável

\section{Fonte: Portal ePORTUGUÊSe ${ }^{4}$}

wordpress.com/ Acesso em 23 jul. 2015

3 Portal Colégio Web. Disponível em: www.colegioweb.com.br Acesso em 23 jul. 2015

4 Portal ePORTUGUÊSe. Disponível em: <eportuguese.blogspot.com. br> Acesso em 23 jul. 2015
O objetivo desse evento foi garantir um compromisso de natureza política para possibilitar o desenvolvimento sustentável e enfrentar os recentes desafios (UNITED NATIONS, 2012). Faz-se necessário destacar que 0 documento final denominado "The future we want" foi objeto de críticas, especialmente por parte da União Europeia, que o avaliou como pouco ambicioso, reforçando a inclusão de medidas de sustentabilidade nas contas nacionais e a falta da obrigatoriedade das empresas em publicar um relatório de sustentabilidade (SERODIO; ENNES, 2012).

Na segunda década do século XXI tem-se discutido a questão envolvendo o aquecimento global e os seus reflexos na elevação da temperatura da água do mar, notadamente na região equatorial, impactando no desenvolvimento dos peixes da região, com consequências diretas na sobrevivência e na segurança alimentar das comunidades que retiram seu sustento da piscicultura.

Em estudo produzido na Universidade James Cook, localizada em Queensland, Austrália, os cientistas analisaram o impacto do aumento da temperatura da água em larvas de peixes colhidas em área de dois mil quilômetros, localizada entre o sul da Grande Barreira de Coral e o Norte do arquipélago de Papua Nova Guiné, região situada próxima à linha do Equador (PORTAL EBC, 2015). 0 estudo em questão relata que a maioria dos peixes marinhos percorre uma etapa de desenvolvimento da larva em mar aberto, fato que os torna mais expostos aos predadores. Se essa situação se prolonga por muito tempo, a possibilidade de sobrevivência é diminuída. Nesse contexto, o coautor da pesquisa, Philip Munday, advertiu para a fragilidade dos peixes equatoriais frente ao aquecimento global, ao passo que outro pesquisador, Geoffrey Jones, alertou para o fato de que milhões de pessoas nas zonas equatoriais encontram-se em relação de dependência com a pesca para viverem (PORTAL EBC, 2015).

A questão ambiental tem se manifestado como objeto de interesse da ciência econômica, contudo, para Cavalcanti (2002), é recente o fortalecimento da economia ambiental e da economia ecológica. Segundo o autor em tela, a economia ambiental está relacionada à visão econômica do ambiente, especialmente pela atribuição de valor econômico aos serviços ambientais e ao capital da natureza, pela internalização de fenômenos que os economistas reputam como fora da alçada própria dos fatores incumbidos da atividade econômi- 
ca. Nesse aspecto, Cavalcanti (2002) argumenta que a economia ecológica debruça-se sobre a visão do processo econômico sob a perspectiva da natureza ou do ecossistema.

Esquematizado na Figura 5, Quintal et al. (2013) observam que questão ambiental produz impactos na sociedade como um todo, independente de nível econômico e social, tornando-se um elemento chave para a reformulação dos valores em vigor na sociedade, produzindo novas formas de ação em todas as práticas produtivas.

\section{ECONOMIA VERDE}

O sistema econômico impõe dupla pressão sobre o meio ambiente, captando seus recursos - alguns indubitavelmente esgotáveis - e despejando na natureza a cada momento os resíduos resultantes de ação humana. Nesse contexto, a concepção do mito do desenvolvimento econômico, formulada por Celso Furtado, está associada com o fato de que o modelo da economia em expansão aniquila e promove a degradação em larga escala do meio ambiente, bem como conduz a ilusão de que, com o crescimento da economia, verifica-se o desenvolvimento (CAVALCANTI, 2002).

Para Gallo et al (2013), a economia verde prescreve a valorização e o fomento a atividades com reduzido teor de emissão de carbono, racionalização dos recursos, integração social, proteção e fortalecimento da biodiversidade e dos serviços aprovisionados pelos ecossistemas.

Misoczky e Bohm (2012) argumentam que a economia verde, definição central do documento "The future we want" (UNITED NATIONS ORGANIZATION, 2012 apud MISOCZKY; BOHM, 2012, p. 556), é conceituada como uma "economia de baixo carbono, eficiente no uso de recursos naturais e socialmente inclusiva" (UNITED NATIONS ENVIRONMENT PROGRAMME, 2011, p. 16 apud MISOCZKY; BOHM, 2012, p. 556). Verdadeiramente, a alusão à temática da inclusão social e a menção, por ocasião da chamada oficial da Rio+20, ao desenvolvimento sustentável e à eliminação da pobreza, denotam uma imprescindível concessão discursiva às reservas geradas, especialmente na comunidade internacional de Organizações não governamentais, contra uma abordagem rigorosamente econômica.

No documento "Rumo a uma economia verde", do Programa das Nações Unidas para o Meio Ambiente (PNUMA), são definidos dez setores para investimentos prioritários, com o propósito de viabilizar práticas mais sus- tentáveis, sem inibir o progresso econômico, conforme apresentado na Figura 5.

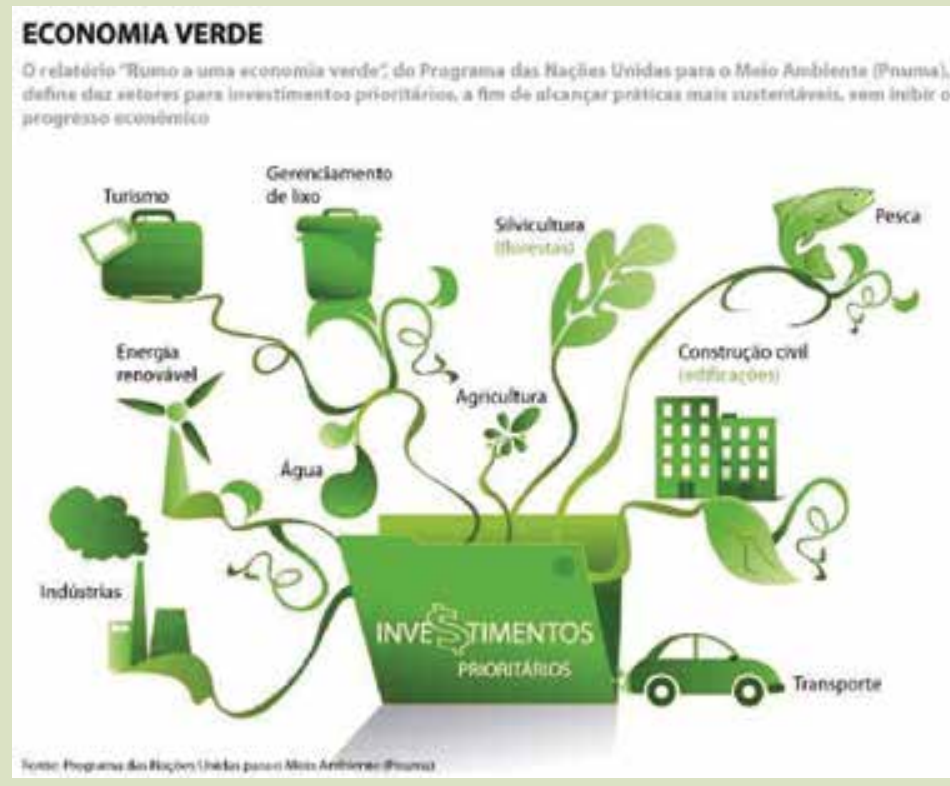

- Figura 5: Setores para investimentos prioritários

- Fonte: Programa das Nações Unidas para o Meio Ambiente (PNUMA) apud Portal Estado de Minas ${ }^{5}$

Gallo et al (2013) destacam que, na mudança para essa nova economia, muitos empregos foram extintos, contudo, novos postos, denominados verdes, seriam abertos, nos quais o trabalhador teria liberdade, remuneração equitativa, segurança no local de trabalho e assistência social. Para tal, os governos precisariam articular o incentivo acertado empregando dispositivos econômicos, normas, inovação e difusão tecnológica, políticas distributivas e voluntárias e iniciativas que sejam capazes de viabilizar a canalização de investimentos - públicos e privados - para segmentos específicos, bem como incrementar sua eficácia e equidade.

Para Gallo et al (2013), na teoria, todos os países aufeririam ganhos econômicos diretos ao levarem adiante a transição para uma economia verde, por intermédio de maior produtividade, otimização de recursos, elevação de empregos a partir da inovação e da criação de mercados e atividades verdes. As conveniências de uma economia verde possibilitariam maior saúde e bem-estar com menor poluição.

A controvérsia acerca do tema está presente nos argumentos de Misoczky e Bohm (2012), as quais entendem

5 Portal Estado de Minas. Disponivel em: http://www.em.com.br/ Acesso em 23 jul. 2015. 
que, à semelhança do que ocorreu com o desenvolvimento sustentável, economia verde igualmente é um termo vago e impreciso. Löwy (2012, p. 2 apud Misoczky e Bohm, 2012, p. 556), em entrevista, afirmara que "ou se trata de uma economia capitalista ou de uma economia não capitalista". Em um contexto de economia verde, "não é outra coisa do que uma economia capitalista de mercado que busca traduzir em termos de lucro e rentabilidade algumas propostas".

Almeida (2012, p. 94 apud Misoczky e Bohm, 2012, p. 556) apresenta que, no âmbito teórico, a economia verde não representa um novo conceito, mas tão somente a recomendação de um complexo de instrumentos e a renovação de ideias já vistas na literatura sobre economia do meio ambiente. Reflete que a única novidade residiria no avizinhamento de abordagens da economia neoclássica e evolucionária com teóricos da estratégia corporativa.

Em última análise, para Diniz e Bermann (2012), é possível afirmar que não existe consenso entre os economistas a respeito da economia verde e suas bandeiras. Nesse contexto, pode-se dizer que o debate ainda encontra-se em curso:

\section{CONTABILIDADE AMBIENTAL}

Maciel et al (2009) e Santos (2001) afirmam que a contabilidade ambiental representa uma ferramenta responsável pelo auferimento dos resultados para as atividades das empresas conectadas ao meio ambiente, valendo como indicativo para reorientar políticas em prol de um desenvolvimento sustentável. A Figura 6 apresenta uma ilustração acerca da seara da contabilidade ambiental.

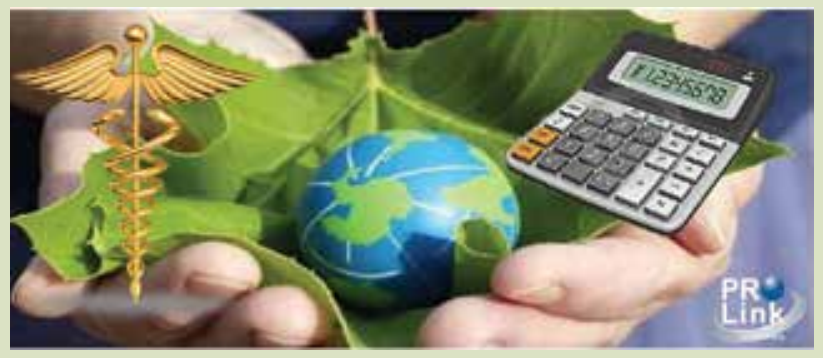

- Figura 6: Contabilidade ambiental

$\square$ Fonte: Portal Prolink Contábil ${ }^{6}$

6 Portal Prolink Contábil. Disponível em: www.prolinkcontabil.com.br Acesso em 23 jul. 2015.
A contabilidade ambiental, no que tange ao registro e à demonstração dos impactos ambientais, consiste em distinguir os registros e as evidenciações das informações acerca do desempenho ambiental da empresa, enumerando de modo categórico os custos ambientais e comprovando sua evolução no transcurso do tempo, disponibilizando, igualmente, estimativas oficiais endossadas pela alta administração da empresa sobre a suficiência dos investimentos ambientais no que tange aos volumes requeridos para minorar os impactos de suas operações no meio ambiente.

Nesse contexto, Santos et al (2001) empreenderam uma pesquisa acerca da aplicabilidade da Contabilidade Ambiental a empresas brasileiras. Identificaram que um restrito quantitativo de empresas brasileiras emprega a contabilidade na sua gestão ambiental. Contudo, o capital objetivo da confecção da pesquisa foi averiguar qual o estágio de aprimoramento da Contabilidade Ambiental nas organizações brasileiras. Ao término de uma revisão bibliográfica acerca da temática, os autores em comento realizaram uma pesquisa de campo, que consistiu no encaminhamento de um questionário aos departamentos de contabilidade de organizações industriais potencialmente poluidoras. 0 universo do estudo abarcou as entidades elencadas no guia "As 500 maiores empresas do Brasil", edição 2000, da revista Exame, sendo a amostra constituída por 50 empresas, cujo faturamento, em 2000, ultrapassou US\$ 50 bilhões. Os autores depreenderam que a união entre organizações empresariais e Universidades é imprescindivel, no sentido de fortalecer pesquisas acerca da Contabilidade Ambiental.

Por meio de uma pesquisa exploratória e descritiva, Varelo et al (2011) examinaram o ensino de contabilidade ambiental nas instituições de ensino superior brasileiras, tendo como objetivo geral investigar a oferta da disciplina em questão nos cursos de Graduação em Ciências Contábeis no Brasil, considerando a inserção da referida disciplina na estrutura curricular dos aludidos cursos de graduação. Os achados apontaram para a limitada oferta da disciplina na estrutura curricular das Instituições de Ensino Superior (IES) do Brasil, presente em apenas $27 \%$ destas. Igualmente, identificaram que naquelas IES em que a disciplina é disponibilizada, há a sua obrigatoriedade na estrutura curricular, sendo a mesma frequentada entre o quinto e o sexto período do curso.

Em última análise, Quintal et al (2013) concluem que a contabilidade ambiental ainda é uma temática que recebe pouca adesão no âmbito das IES, apesar do seu vasto campo de atuação em função da sua interdisciplinaridade, bem como 
pela florescente preocupação por parte da sociedade com a mensuração e registro dos impactos ambientais.

\section{PERSPECTIVAS FUTURAS NA SEARA AM- BIENTAL PARA GRADUANDOS EM CIÊNCIAS CONTÁBEIS}

No Brasil, relevantes ferramentas para gestão dos recursos naturais têm sido desenvolvidas. A título de ilustração, convém destacar a promulgação pela Presidência da República da Lei $n^{\circ} 12.561$, que versa sobre o uso sustentável da vegetação nativa (BRASIL, 2012 apud QUINTAL et al, 2013). Outros estímulos ao desenvolvimento de tecnologias que amenizem os gastos ambientais são suscitados por órgãos de fomento à pesquisa, tal qual o Conselho Nacional de Desenvolvimento Científico Tecnológico (CNPq). Vinculado ao Ministério da Ciência, Tecnologia e Inovação (MCTI), - CNPq envolve-se no estabelecimento de programas de pesquisa e difusão da Política Nacional de Ciência e Tecnologia (QUINTAL et al, 2013).

Dentre os programas empreendidos pelo CNPq, está o Programa Ciência sem Fronteiras (PCsF), este programa procura, por intermédio de intercâmbio internacional, alicerçar a ciência, a tecnologia, e a inovação incrementando a competitividade brasileira no cenário global. Como áreas prioritárias, o PCsF abarca distintos setores com foco em meio ambiente, especialmente: energias renováveis e tecnologias de prevenção e mitigação de desastres naturais (QUINTAL et al, 2013).

Propagado por meio da cooperação entre o MCTI e o Ministério da Educação (MEC), por mediação de instituições responsáveis por fomentar e incentivar a pesquisa científica, CNPq e a Coordenação de Aperfeiçoamento de Pessoal de Nível Superior (CAPES) e das Secretarias de Ensino Superior e de Ensino Tecnológico do MEC, o PCsF foi lançado em julho de 2011 e formalizado pelo Decreto $n^{0} 7.642$, de 13 de dezembro de 2011. Esse programa tem como propósito promover o desenvolvimento tecnológico e a inovação no Brasil. Para tanto, induz o intercâmbio e a mobilidade internacional (QUINTAL et al, 2013).

De forma explícita, não se percebe a Contabilidade presente no escopo do programa, contudo deve-se examiná-la sob o espectro da transversalidade. Como exemplo de disciplina que propicia esta visão interdisciplinar pode-se destacar a Contabilidade Ambiental que, como objetivo, busca mensurar os eventos econômicos das instituições que contemplem o meio ambiente (FERREIRA, 2006 apud QUINTAL et al, 2013).

É nesse contexto que se espera que os graduandos em Ciências Contábeis possam usufruir das oportunidades, não apenas no mercado de trabalho, mas também na área acadêmica.

\section{CONSIDERAÇÕES FINAIS E CONCLUSÕES}

O objetivo do presente estudo foi o objetivo do presente estudo é traçar um breve panorama acerca das temáticas afetas ao desenvolvimento econômico, economia verde e contabilidade ambiental.

A despeito dos avanços observados nas últimas décadas, verifica-se que há um longo caminho a ser trilhado, haja vista que em pleno século XX1 observam-se ações humanas responsáveis por grandes prejuízos ao meio ambiente e à coletividade que dele depende.

A questão ambiental tem se manifestado como objeto de interesse da ciência econômica, contudo é recente o fortalecimento da economia ambiental e da economia ecológica. Contudo, críticas têm sido formuladas no sentido de que, analogamente ao que ocorreu com o desenvolvimento sustentável, economia verde igualmente é um termo vago e impreciso. Adicionalmente, a economia verde não representaria um novo conceito, mas tão somente a recomendação de um complexo de instrumentos e a renovação de ideias já vistas anteriormente.

Pode-se perceber que a questão ambiental, especialmente na seara da Contabilidade Ambiental, ainda não foi alçada ao protagonismo em organizações empresariais e em Instituições de Ensino Superior, apesar da gradativa importância que a temática vem adquirindo com o transcurso do tempo.

É certo que a questão ambiental produz impactos na sociedade como um todo, independente de nível econômico e social, tornando-se um elemento chave para a reformulação dos valores em vigor na sociedade, produzindo novas formas de ação em todas as práticas produtivas.

Em última análise, a despeito da diversidade de entendimentos e formulações teóricas, indubitavelmente existe um extenso caminho a ser percorrido para a plena inserção da questão ambiental no seio empresarial e acadêmico, especialmente no que tange às possibilidades de contribuição da economia e da contabilidade. 


\section{REFERÊNCIAS}

BONENTE, B. I. A Economia do Desenvolvimento em Perspectiva Histórica: novos rumos da disciplina. 2007. 103f. Dissertação (Mestrado) - Curso de Pós-Graduação em Economia, Unniversidade Federal de Uberlândia, Uberlândia, 2007.

CAMPOS, M. M. da C. e. Processo de desenvolvimento local: uma análise da implementação do projeto aliança com o adolescente. 173 p. Dissertação. Programa de Pós-graduação em Administração. Escola de Administração da Universidade Federal da Bahia. Salvador, 2003.

CARVALHO, M. O Desenvolvimento Local e a Imigração Cabo-verdiana: um olhar sobre a comunidade da Cova da Moura. Dissertação. Programa de Pós-graduação em Desenvolvimento, Diversidades Locais e Desafios Mundiais. Lisboa: ISCTE, 2010.

CAVALCANTI, C. Meio ambiente, Celso Furtado e o desenvolvimento como falácia. Ambiente e Sociedade. Vol. V, 2 , agosto-dezembro 2002; vol. VI, 2, janeiro-julho 2003. Campinas: Universidade de Campinas.

CLUB OF ROME. 40 years “limits to growth". Disponível em: <http://www.clubofrome. org/?p=326>. Acesso em: 23 jul. 2015.

DINIZ, E. M.; BERMANN, C. Economia verde e sustentabilidade. Estudos avançados, v. 26, n. 74, p. 323-330, 2012.

GALLO, E. et al . Saúde e economia verde: desafios para o desenvolvimento sustentável e erradicação da pobreza. Ciênc. saúde coletiva, Rio de Janeiro , v. 17, n. 6, p. 1457-1468, Jun. 2012.

GIL, A. C. Como elaborar projetos de pesquisa. 5. ed. São Paulo: Atlas, 2010.

MACANA, E. C. Impactos potenciais da mudança climática no desenvolvimento humano: uma análise baseada na Abordagem das Capacitações. 2008. 242f. Dissertação (Mestrado) - Curso de Pós-Graduação em Economia, Úniversidade Federal do Rio Grande do Sul, Porto Alegre, 2008.
MACIEL, C. V. et al. Contabilidade ambiental: um estudo exploratório sobre o conhecimento dos profissionais de contabilidade. Rev. Contemporânea Contabilidade, v. 7, n. 11, p. 137-158, 2009.

MISOCZKY, M. C.; BOHM, S. Do desenvolvimento sustentável à economia verde: a constante e acelerada investida do capital sobre a natureza. Cad. EBAPE. BR, v. 10, n. 3, p. 546568,2012

PORTAL EBC. Agência Brasil. Aquecimento global afeta desenvolvimento dos peixes na zona equatorial. Artigo. 31 mar. 2015. Disponível em: < http://agenciabrasil.ebc.com.br/ internacional/noticia/2015-03/aquecimento-global-afeta-desenvolvimento-dos-peixes-na-zona-equatorial> Acesso em 23 jul. 2015

QUINTAL, R. S. et al. A inserção da contabilidade ambiental no contexto universitário brasileiro de ciência, tecnologia e inovação. Rama: Revista em Agronegócio e Meio Ambiente, v. 6, p. 533-551, 2013. Disponível em: http://periodicos.unicesumar.edu.br/index.php/rama/article/view/2589/2041 Acesso em 20 dez. 2014.

SANTOS, A. O. et al. Contabilidade ambiental: um estudo sobre sua aplicabilidade em empresas brasileiras. Rev. Contab. Finanç., v. 1, p. 34-56, 2001.

SERODIO, G.; ENNES, J. Documento "o futuro que queremos" é aprovado na Rio+20. Valor Econômico. São Paulo. Disponível em: <http://www.valor.com.br/rio20/2725434/ documento-o-futuro-que-queremos-e-aprovado-na-rio20\#ixzz1yild1rqQ>. Acesso em 23 jul. 2015.

UNITED NATIONS. Rio+20: United Nations Conference on Sustainable Development. Disponivel em: < http://www. uncsd2012.org/>. Acesso em: 23 jul. 2015.

VARELO, E. M. et al. O ensino da contabilidade ambiental nas instituições de ensino superior brasileiras. In: CONFERENCE SOUUTH AMERICA, 2., 2011, Ribeirão Preto. Anais... Ribeirão Preto: CSEAR, 2011
Recebido em: 03 JAN 2015

Aprovado por Double Blind Review em: 20 SET 2015
Como citar este documento:

QUINTAL, R. S.; CONDÉ, R. A. D.; SANTOS, M. dos; LEAL, R. B.; GOMES, C. F. S. Considerações sobre Desenvolvimento Econômico, Economia Verde e Contabilidade Ambiental: uma abordagem introdutória. Revista PAGMAR, Rio de Janeiro, v. 4, n. 4, p. 74 - 81, jan./dez. 2016. 